\title{
Michel Foucault e a analítica da finitude
}

\author{
Michel Foucault and the analytic of finitude
}

\section{Rodrigo Barbosa Lopes*}

Universidade Estadual Paulista (UNESP), Presidente Prudente, São Paulo, Brasil

\section{Resumo}

Em Les mots et les choses, Foucault (1996) procedeu, por meio da pesquisa arqueológica, a uma investigação acerca da constituição histórica dos saberes sobre o homem. Isso significa dizer que, na verdade, não se tratava de uma história das Ciências Humanas, mas de uma investigação na qual elas fossem tomadas como instituições, enquanto práticas ou discursos que definem o homem como objeto de um saber possível, a partir principalmente das ciências empíricas - biologia, economia política e filologia - que o analisam nas relações fundamentais com a vida, o trabalho e a linguagem; e, por outro lado, a reflexão filosófica que o admite como sujeito e fundamento de todas essas positividades. Com o objetivo de elaborar uma arqueologia das Ciências Humanas, caracterização a mais geral de Les mots et les choses, Foucault ponderou que o objetivo pretendido por essa análise não poderia decorrer simplesmente de uma história das ideias ou das ciências. Na verdade, o nível arqueológico de análise permitiu descobrir e avaliar os sistemas de saber subjacentes às três grandes fases do pensamento

\footnotetext{
* RBP: Doutor em Educação, e-mail: amitiphi@outlook.com
} 
ocidental, convencionalmente chamadas pelo filósofo de Renascença, a Época Clássica e a Modernidade. No caso da Modernidade, Foucault a definiu como a Idade do Homem e procurou demonstrar de que modo nesta épistémè o homem é, ao mesmo tempo, sujeito e objeto total de seu próprio saber. Este é o problema ao qual se volta a crítica de Foucault à estrutura antropológico-humanista do pensamento moderno, que passamos a analisar neste artigo admitindo, para tanto, a indicação de um estudo dos modos de problematização e a centralidade que a analítica da finitude ocupa nesta tarefa filosófica de diagnosticar a atualidade.

Palavras-chave: Analítica da finitude. Antropologia. Problematização.

\section{Abstract}

In Les mots et les choses, Foucault (1996) proceded through archaeological research to an investigation of the historical development of knowledge about man. This means that, in fact, it was not a story of the Human Sciences, but an investigation in which they were taken as institutions, as practices or discourses that define man as an object of possible knowledge from mainly the empirical sciences - biology, political economy and philology - that analyze the fundamental relations with the life, work and language; and, on the other hand, philosophical reflection that admits it as subject and foundation of all these positive aspects. With the objective of developing an archeology of the Human Sciences, the most general characterization of Les mots et les choses, Foucault argued that the intended purpose of this analysis could not be due simply to a history of ideas or the sciences. In fact, the archaeological level analysis allowed to discover and evaluate the systems of knowledge underlying the three great stages of Western thought, conventionally called by the philosopher the Renaissance, the Classical Era and Modernity. In the case of Modernity, Foucault defined it as the Age of Man and sought to demonstrate how in this épistémè the man is, at the same time, subject and object of all their own knowledge. This is the problem that turns Foucault's critique to the anthropologic-humanist structure of modern thought, which we will analyze in this article admitting, therefore, an indication of a study of ways of questioning and the centrality that the analytic of finitude takes this philosophical task of diagnosing the present.

Keywords: Analytic of finitude. Anthropology. Problematization. 


\section{Introdução}

Em Le souci de la vérité, o tratamento que Foucault deu aos temas analisados por ocasião das perguntas que lhe foram dirigidas nos faz lembrar, oportunamente, "que sempre se chega ao essencial retrocedendo" (2001b, p. 1488). Esta maneira de entender o exercício da leitura e da escrita filosófica apresenta o trabalho do pensamento, ou o trabalho sobre o pensamento, ao modo de uma regressão e de uma proliferação, admitidas em um mesmo movimento. Revisitar os conteúdos trabalhos e, antes deles, o projeto delineado para o trabalho de pesquisa, é, pois, dar ciência ao que foi modificado no modo de pensar os problemas e também a respeito do que deles se pensava em termos de conteúdo, tanto quanto descobrimos que esse exercício de pensamento não deixou de modificar a experiência e, em razão da qual, inclusive, nós mesmos nos vemos modificados ao final do processo.

Foucault talvez tenha sido o filósofo contemporâneo que mais bem compreendeu que essa tarefa de uma filosofia do porvir deveria assumir as feições de um trabalho crítico do pensamento como diagnóstico da atualidade, o que ele apropriadamente chamou de "ontologia do presente" (2001b, p. 1506) ou de "ontologia crítica de nós mesmos" (2001b, p. 1396), e que, enquanto atividade filosófica de investigação do presente, de análise da constituição histórica de nossa subjetividade, apenas poderia se apresentar na forma de uma atitude crítica como problematização do pensamento. No mais, esta seria a contribuição que Foucault poderia prometer a uma filosofia então lastreada por um estudo dos modos de problematização: a possibilidade do enfretamento com as questões, com as práticas históricas e com os acontecimentos que agem nos processos de constituição da subjetividade; e, por esse motivo, uma ontologia histórica sobre a nossa constituição como sujeitos de experiência.

O próprio Foucault reconheceu, ao fazer uma referência remissória às suas publicações, que a noção que unificava todos os estudos por ele realizados desde Histoire de la folie é a de "problematização", embora ele não a tivesse ainda isolado suficientemente, tal como ele 
viria a fazer, depois, nos trabalhos da década de 1980. Em Le souci de la vérité, por exemplo, Foucault esclareceu que:

Problematização não quer dizer representação de um objeto preexistente, nem tampouco a criação pelo discurso de um objeto que não existe. É o conjunto das práticas discursivas ou não discursivas que faz alguma coisa entrar no jogo do verdadeiro e do falso e o constitui como objeto para o pensamento (seja sob a forma da reflexão moral, do conhecimento científico, da análise política, etc.) (2001b, p. 1489).

Com efeito, Deleuze (1988, p. 124) nos fez lembrar algo de fundamental no estudo que dedicou à compreensão da filosofia de Michel Foucault, e o fez de um modo tal que até parecia revelar algo que Foucault tivesse dito secretamente, ao modo de uma confissão entre amigos, que apesar das idas e vindas sobre as questões do sujeito com relação à verdade, ao poder e consigo, era o pensamento, o exercício do pensamento como "problematização" e "experimentação" que interessava a Foucault ${ }^{1}$ e que, ademais, o levaria a esclarecer, sobretudo nos dois últimos anos de sua vida, que seu trabalho filosófico tinha a ver precisamente com isso: “O estudo dos (modos de) problematizações (isto é, do que não é constante antropológica nem variação cronológica) é, portanto, a maneira de analisar, em sua forma historicamente singular, questões de alcance geral." (FOUCAULT, 2001b, p. 1396).

É particularmente importante considerar o modo com o qual ele caracterizou a tarefa da Filosofia contemporânea e a sua própria filosofia, ou seja, como uma atitude filosófica ou um modo de interrogação crítica sobre o presente que põe em evidência ao menos duas questões fundamentais: O que é a nossa atualidade? Qual o campo atual das experiências possíveis? A definição desta atividade filosófica como

\footnotetext{
Falamos, evidentemente, a partir de Deleuze (1988) e de seu ponto de vista. Mas o próprio Foucault nos autoriza a inferir de seus últimos trabalhos - destacadamente What is Enlightenment?, Polémique, politique et problématisations, e Le souci de la vérité, todos datados de 1984 e publicados em Dits et Écrits II - 1976-1988 (FOUCAULT, 2001b) - que a atividade filosófica como 0 estudo dos modos de problematização norteara as suas escolhas e a conduta em face dos desafios supervenientes de seu problema geral de pesquisa. Por força desse esclarecimento, se 0 trabalho filosófico de Foucault se volta, pois, constantemente ao problema das "relações entre o sujeito, a verdade e a constituição da experiência" (FOUCAULT, 2001b, p. 1550), tanto mais importaria destacar a questão do sujeito e as práticas históricas de sua constituição como um problema central de sua filosofia.
} 
diagnóstico da atualidade tem, com efeito, a garantida de sua "coerência metodológica" com base num estudo ao mesmo tempo arqueológico e genealógico das práticas históricas de constituição dos campos de experiência e de nossa subjetividade; uma "coerência teórica" lastreada pelas formas historicamente singulares com as quais se tem problematizado as relações gerais de nosso pertencimento ao presente, nelas consideradas igualmente as nossas relações com a verdade, com a política e a moral; e ainda uma "coerência prática" resultante da confrontação da reflexão filosófica, de caráter histórico-crítico, com o campo real das experiências e das práticas concretas (FOUCAULT, 2001b, p. 1396-1397). Além daquelas duas expressões, Foucault utiliza também "ontologia da atualidade" (2001b, p. 1507) e é quanto a esta última indicação que o vemos, finalmente, afirmar: "[...] a filosofia como problematização de uma atualidade e como interrogação pelo filósofo desta atualidade da qual ele faz parte e com relação à qual ele tem que se situar [...]." (2001b, p. 1499-1500).

O que é preciso esclarecer, ademais, é que toda essa concepção de filosofia como diagnóstico da atualidade e como ato de problematização tem a ver intrinsecamente, estando inclusive por ela compreendida, com a elaboração de uma história do pensamento. Foucault recorreu frequentemente à noção de problematização para distingui-la, no essencial, de uma história das ideias, ou seja, da análise dos sistemas de representação; e de uma história das mentalidades, isto é, da análise das atitudes e dos esquemas de comportamento. "[...] O pensamento não é o que habita uma conduta e lhe dá um sentido; é, sobretudo, aquilo que permite tomar uma distância em relação a essa maneira de fazer ou de reagir, e tomá-la como objeto de pensamento e interrogá-la sobre seu sentido, suas condições e seus fins." (2001b, p. 1416). Colocar, pois, a problematização sob o signo de uma história do pensamento é, por seu turno, interessar-se, sobretudo, pela maneira com que se constituem os campos de experiência e os problemas que são colocados para o pensamento, ao mesmo tempo em que se procura discernir as estratégias com as quais são desenvolvidas as respostas possíveis. Com efeito, a um mesmo conjunto de dificuldades diversas respostas podem ser dadas; e, na maior parte do tempo, elas são efetivamente propostas. 
Contudo, como esclareceu Foucault, "[...] o que é preciso compreender é aquilo que as torna simultaneamente possíveis; é o ponto no qual se origina sua simultaneidade; é o solo que pode nutrir umas e outras, em sua diversidade, e, talvez, a despeito de suas contradições." (2001b, p. 1416-1417).

Em que pesem tais afirmações, algumas considerações preliminares se fazem relevantes. A respeito da obra Michel Foucault, o nível arqueológico de suas pesquisas permitiu descobrir e avaliar os sistemas de saber subjacentes às três grandes fases do pensamento ocidental, convencionalmente chamadas pelo filósofo de Renascença, a Época Clássica e a Modernidade. Com o objetivo de elaborar uma arqueologia das Ciências Humanas, caracterização a mais geral de Les mots et les choses, Foucault (1966) ponderou que o objetivo pretendido por essa análise não poderia decorrer de uma história das ideias ou das ciências. Na verdade, a arqueologia como método pretendia ser um estudo com o qual fosse possível descobrir:

[...] a partir de que conhecimentos e teorias foram possíveis; segundo qual espaço de ordem se constituiu o saber; na base de qual a priori histórico e no elemento de qual positividade ideias puderam aparecer, ciências se constituir, experiências se refletir nas filosofias, racionalidades se formar [...]. (FOUCAULT, 1966, p. 13).

No caso da Modernidade, Foucault a definiu como a Idade do Homem e procurou demonstrar de que modo nesta épistémè o homem é ao mesmo tempo sujeito e objeto total de seu próprio saber, concluindo que "[...] nossa cultura atravessou o limiar a partir do qual reconhecemos nossa modernidade no dia em que a finitude foi pensada numa infindável referência a si mesma." (1966, p. 329). Essa configuração antropológica da filosofia moderna consistia, argumentava Foucault, em um desdobramento do dogmatismo: "[...] a análise pré-crítica do que é o homem em sua essência se torna a analítica de tudo o que pode se dar em geral à experiência do homem." (1966, p. 352). Assim, a tese de que os limites do conhecimento fundam positivamente a possibilidade do saber, que já podia ser encontrada em Kant (2001), Foucault chamou de uma analítica da finitude e da existência humana: 
Assim, redescobrindo a finitude na interrogação da origem, o pensamento moderno fecha o grande quadrilátero que começou a desenhar quando toda a épistémè ocidental basculou no final do século XVIII: a ligação das positividades à finitude, a reduplicação do empírico no transcendental, a relação perpetua do cogito ao impensado, o distanciamento e o retorno da origem definem para nós o modo de ser do homem. É sobre a análise desse modo de ser, e não mais sobre a da representação que desde o século XIX a reflexão procura fundar filosoficamente a possibilidade do saber (1966, p. 346).

Iniciamos, pois, este artigo com uma reflexão acerca do surgimento e da elaboração de um domínio de questionamentos sobre o homem para o qual o conceito de finitude humana é constitutivo do que poderíamos chamar de uma antropologia filosófica. Logo de partida é possível reconhecer na formação histórica desse regime de saber, que Foucault (1966) chamou, em Les mots et les choses, de "analítica da finitude", a configuração antropológica própria às Ciências Humanas, e mesmo que na atualidade elas renunciem a este passado, ainda é possível encontrar nelas os efeitos desta concepção. Para a enunciação desse problema específico que se estende ao campo do pensamento filosófico contemporâneo, admitamos inicialmente o modo como Foucault o caracterizou em duas entrevistas a partir das quais podemos entrever a indicação de uma análise possível.

\section{A analítica da finitude}

Uma primeira aproximação com o assunto pode ser buscada na entrevista concedida a Alain Badiou, intitulada Philosophie et psychologie ${ }^{2}$,

2 As entrevistas utilizadas para este artigo constam da edição Quarto de Dits et écrits (2001), publicada pelas Éditions Gallimard. Esta nova edição reagrupa, em dois volumes, os quatro volumes estabelecidos pela Bibliothèque des Sciences Humaines, em 1994. Para a presente edição, o primeiro volume reúne os textos de Michel Foucault publicados de 1954 a 1975 e, o segundo volume, os textos publicados de 1976 a 1988. Acerca do texto Philosophie et psychologie, a entrevista provém de emissões produzidas pela radio-télévision scolaire de 1965 a 1966, concebidas por Dina Dreyfus e realizadas por Jean Fléchet (Dossiers pédagogiques de la radio-télévision scolaire, 27 février 1965, p. 65-71). Para consulta, utilizamos a tradução para o francês disponível em Dits et écrits I (FOUCAULT, 2001a, p. 466-476). 
de 1965. Encontramos neste texto muitas questões que Foucault (2001a) faz passar por um exame crítico das relações que podem ser pensadas e mantidas entre a Filosofia e a Psicologia. Damos uma atenção especial a duas delas: é perguntado ao filósofo o que é a Psicologia, e se existem relações interiores e exteriores entre a Psicologia como forma cultural e a Filosofia como forma cultural. Contudo, a respeito do surgimento na história de um período conhecido como Modernidade, a questão de se as Ciências Humanas são formas culturais que pretendem se fundar sobre um saber positivo acerca do homem e das coisas humanas forma, junto a outras interrogações, um conjunto bem definido de problemas ao qual Foucault dispensou um estudo extenso e erudito apenas um ano depois, com a publicação de Les mots et les choses.

Com efeito, Foucault fez uma ponderação acerca da tentativa de definir a Psicologia como uma ciência, e sugeriu que talvez ela tivesse mais a ver com uma forma cultural, no que isso tem de aproximação com toda uma série de fenômenos conhecidos pela história do Ocidente como de natureza cultural. No entanto, é a respeito da segunda questão que verificamos a indicação de uma resposta para a identificação da Filosofia e da Psicologia como formas culturais. Depois de considerar que talvez um dos grandes problemas o qual temos de enfrentar atualmente é a compreensão da Filosofia como "[...] a forma cultural a mais geral na qual poderíamos refletir sobre o que é o Ocidente." (FOUCAULT, 2001a, p. 466), o filósofo reconheceu, em primeiro lugar, que de fato a Psicologia, e por meio desta, as Ciências Humanas em geral estão, desde o século XIX, em uma relação de aproximação e cruzamento com a Filosofia; talvez numa relação de certa dependência das primeiras com a Filosofia. Pergunta Foucault, "[...] Esse entrelaçamento da filosofia e das ciências humanas, como podemos concebê-lo?" (2001a, p. 467).

Uma resposta possível é concordar com a tese de que a Filosofia, no decorrer de sua história, circunscreveu junto ao campo dos saberes filosóficos um domínio de conhecimento reservado ao estudo da alma ou do pensamento, no geral, e que agora as Ciências Humanas estariam mais bem preparadas para investigar de um modo claro, metódico e 
positivo o que a Filosofia guardava apenas aos assuntos de metafísica. Isso quer dizer, nas palavras de Foucault, "[...] que a velha tarefa filosófica que havia nascido no Ocidente com o pensamento grego, esta velha tarefa deve agora ser retomada com os instrumentos das ciências humanas." (2001a, p. 467). Mas Foucault denuncia, precisamente, que essa tomada de posição está intrinsecamente ligada a uma perspectiva filosófica, que é o positivismo. E quanto a isso, o filósofo não negligenciou o fato em Les mots et les choses do quanto o positivismo tem de semelhante à analítica da finitude, por pretender encontrar a verdade objetiva sobre o homem em ciências positivas, como se ela pudesse ser reduzida a uma causalidade detectável pelas ciências empíricas.

Todavia, é outra a perspectiva que Foucault (2001a) considera enquanto persiste o problema de como explicar o entrelaçamento entre a Filosofia e as Ciências Humanas. No que diz respeito à empresa filosófica e científica, ou apenas cultural, de conhecer o ser do homem e as formas históricas de sua constituição, o que precisa ser considerado cuidadosamente é o fato de que o homem apenas surgiu para o saber ocidental em fins do século XVIII, como um ser empírico-transcendental, isto é, duplamente analisado por saberes que o revelam como um ser vivente, falante e produtivo, por um lado; e também por uma reflexão sobre essas condições materiais e positivas que revelasse, afinal, o ser mesmo do homem, suas diferenças culturais, por exemplo, mas precisamente a unidade dos termos que o faz ser homem: a analítica da finitude. E nisso apenas se poderia reconhecer, no limite possível para o pensamento filosófico, uma antropologia. Analisou Foucault que:

[...] é que isso talvez faça parte do destino da filosofia ocidental que, desde o século XIX, alguma coisa como uma antropologia tenha se tornado possível; quando eu digo antropologia, eu não quero falar dessa ciência particular que chamamos antropologia e que é o estudo das culturas diferentes [extérieures] da nossa; por antropologia, eu entendo esta estrutura propriamente filosófica que faz com que agora os problemas da filosofia estejam todos alojados no interior desse domínio que podemos chamar o da finitude humana (2001a, p. 467). 
Este é um aspecto muito importante. Na verdade, trata-se de um traço histórico fundamental no qual a Filosofia é tomada como a forma cultural a partir da qual todas as ciências do homem são, em geral, possíveis. Isto, advertiu Foucault, é o que devemos pensar, na atualidade e depois, na medida em que ainda não compreendemos bem a nossa estranha dependência a esse modelo ou regime de saberes, de tal modo que ainda o experimentamos como uma necessidade para o pensamento, um paradigma com o qual precisamos romper. Não nos desprendemos completamente dessa imagem antropológica, e ainda dogmática, do pensamento filosófico: "Se não podemos mais filosofar a não ser sobre o homem na qualidade de homo natura, ou ainda enquanto um ser finito, nessa medida, toda filosofia não será, no fundo, uma antropologia?" (FOUCAULT, 2001a, p. 467). O problema, então, que analisamos, adstrito à abordagem da analítica da finitude, é o que Foucault chamou de "estrutura antropológico-humanista do pensamento do século XIX" (2001a, p. 636).

A segunda entrevista que mencionamos no início deste texto, e que igualmente nos abre um campo variado de pensamento sobre o tema, é intitulada Qui êtes-vous, professeur Foucault?³, de 1967. A parte que é preciso analisar é a resposta que Foucault fez à repercussão de um dos temas mais polêmicos suscitado pelo filósofo na obra Les mots et les choses: tratava-se, então, da crítica às ideologias ditas "humanistas". Foucault ponderou o seguinte:

Na tentativa de diagnosticar o presente no qual nós vivemos, podemos isolar como já pertencendo ao passado certas tendências que são ainda consideradas como contemporâneas. É precisamente por isso que se atribuiu um valor polêmico a algumas de minhas análises, que eram para mim somente análises. Vocês se referiram ao meu diagnóstico sobre o humanismo. Em As Palavras e as Coisas, eu procurei seguir as duas direções de pesquisa das quais eu lhes falava: tratava-se de ver como havia podido se constituir um objeto para o "saber" e como tinha funcionado certo tipo de discurso. Eu procurei analisar o seguinte fenômeno:

3 Trata-se da entrevista intitulada "Che cos'è Lei Professor Foucault?", publicada primeiramente em La Fiera letteraria, ano XLII, nº 39, de 28 de setembro de 1967. Para consulta, utilizamos a tradução para o francês disponível em Dits et écrits I (FOUCAULT, 2001a, p. 629-648). 
nos discursos científicos que o homem formulou desde o século XVII, apareceu ao longo do século XVIII um objeto novo: o "homem". Com o homem foi dada a possibilidade de se constituir as ciências humanas. Assistimos, além disso, o aparecimento de uma espécie de ideologia ou de tema filosófico geral que era aquele do valor imprescritível do homem. Quando eu digo valor imprescritível, digo isso em um sentido muito preciso, isto é, que o homem apareceu como um objeto de ciência possível - as ciências do homem - e ao mesmo tempo como o ser graças ao qual todo conhecimento é possível. O homem pertencia então ao campo dos conhecimentos como objeto possível e, por outro lado, estava colocado de maneira radical no ponto de origem de toda espécie de conhecimento (2001a, p. 635-636).

Esta passagem da entrevista, a nosso ver, caracteriza muito bem o que Foucault (1966) chamou de analítica da finitude em Les mots et les choses. Em face da pertinência desse imperativo histórico de nossa cultura nas Ciências Humanas e mesmo para a Filosofia contemporânea, que é o humanismo e suas manifestações culturais, Foucault (2001b) se propôs analisar a forma paradoxal com que ele se manifesta e sob que condições ele pode ainda ser proposto na atualidade. Mas, tão importante quanto o esclarecimento das contradições de que é portadora a estrutura antropológico-humanista do pensamento, é a maneira com que Foucault faz a abordagem do problema e que diz muito sobre como ele iria definir depois, a partir dos trabalhos da década de $1980^{4}$, a sua investigação filosófica. Trata-se, na realidade, de uma transformação profunda no modo de conceber e de fazer filosofia. Segundo ele, depois de Nietzsche a Filosofia tem a tarefa de diagnosticar a atualidade e não mais de procurar dizer uma verdade, ou a verdade sobre tal e tal coisa, e que pudesse valer indefinidamente para os sujeitos e para as épocas. E Foucault faz dessa perspectiva o seu próprio trabalho:

[...] Eu procuro diagnosticar, realizar um diagnóstico do presente: dizer o que nós somos hoje e o que significa, hoje, dizer o que nós dizemos.

4 Fazemos uma menção especial ao texto de Michel Foucault intitulado The Subject and Power, e publicado em Dreyfus \& Rabinow (1983). A edição usada como referência é a tradução para o francês Le sujet et le pouvoir, disponível em Dits et écrits II (FOUCAULT, 2001b, p.1041-1062). 
Este trabalho de escavação sob nossos pés caracteriza desde Nietzsche o pensamento contemporâneo, e nesse sentido eu posso me declarar filósofo (2001a, p. 634).

No mais, a forma paradoxal a que fizemos menção é que aquela estrutura ou modalidade do pensamento filosófico, e que Foucault indicou em Les mots et les choses como o "sono antropológico" no qual adormeceram a Filosofia e as Ciências Humanas (1966, p. 351), é uma perspectiva de pensamento do século XIX, mas que experimentamos confusamente como uma tendência considerada ainda contemporânea. Nesse sentido, vemos Foucault dizer: "A Antropologia constitui talvez a disposição fundamental que comandou e conduz o pensamento filosófico desde Kant até nós." (1966, p. 353). No entanto, tão importante quanto analisar a emergência do tema filosófico geral que Foucault chamou de "valor imprescritível" do homem é o fato ou a situação de que essa imagem do pensamento ${ }^{5}$ está em vias de se desfazer, de se dissociar sob nossos olhos, em face da abertura a um pensamento novo, por vir, talvez um pensamento sem pressupostos.

A esse respeito, Foucault (1966) afirmou que o projeto de conhecer o homem, do qual a antropologia extrairá o programa geral para a pesquisa filosófica, teve, na verdade, início no século XIX. Isso quer dizer que, embora encontremos na história precedente obras que reflitam sobre o ser do homem ${ }^{6}$, elas não o fizeram de um modo absoluto.

5 Sobre a expressão "imagem do pensamento", esclarecemos que se trata de uma referência implícita à obra de Gilles Deleuze a qual está compreendida, por um lado, pelo esforço de crítica a um tipo de pensamento que ele designa sob o sigo geral da representação de imagem dogmática e, por outro, pela constituição de uma filosofia da diferença. Ambas essas atitudes, de crítica e de clínica, apontam para a possibilidade de fazer filosofia que, para Deleuze, consiste ao menos em um duplo investimento: a formulação de problemas e a criação de conceitos. A imagem do pensamento objeto de crítica é uma imagem definida como moral, representativa, racionalista e dogmática, no lugar da qual o filósofo propõe uma nova imagem do pensamento ou um pensamento sem imagem. Indicamos aqui três obras de Deleuze em que esse problema é especificamente tratado: Nietzsche et la philosophie (1983), Proust e os signos (1987) e Différence et répétition (1976).

6 Indicamos aqui, entre outros casos da História da Filosofia, o exemplo de David Hume na obra $A$ treatise of human nature, a qual estava organizada então em três volumes, dos quais os Livros I e II foram publicados em 1739, e o Livro III, juntamente com 0 apêndice, em 1740. Nesta obra, embora haja uma profusão de ideias e argumentos a respeito do homem ou de sua natureza, não há propriamente uma antropologia ou um pensamento filosófico fundado no homem como podemos ver surgir a partir da Modernidade e que, ao modo de uma imagem do pensamento, tem determinado o modo de pensar filosoficamente. Cf. Hume (2001). 
Na verdade, nem depois e nem agora seria permitido fazê-lo. Mas a Modernidade assistiu a uma transformação arqueológica profunda acerca do que é possível pensar e saber sobre os modos de ser do homem, isto é, as positividades por meio das quais o homem pode ser historicamente determinado, seu corpo escrutinizado, a análise da linguagem e das riquezas possível; ao mesmo tempo que a possibilidade e as condições para o conhecimento fossem determinadas em outro lugar, isto é, no homem enquanto sujeito e, portanto, transcendentais ${ }^{7}$. Kant (2001) talvez seja o signo maior que marca o limiar de nossa modernidade e das transformações que assistimos desde então. Nesse mesmo limiar histórico, uma antropologia se tornou possível:

[...] Até o final do século XVIII, isto é, até Kant, toda reflexão sobre o homem é uma reflexão segunda com relação a um pensamento que, ele, é primeiro e que é, digamos, o pensamento do infinito. Tratava-se sempre de responder às questões tais como estas: sendo dado que a verdade é o que ela é, ou que a matemática ou a física nos ensinaram tal ou tal coisa, como pode ser que percebamos como percebemos, que conheçamos como conhecemos, que nos enganemos como nos enganamos? A partir de Kant faz-se o inverso, isto é, que não é a partir do infinito ou da verdade que vamos colocar o problema do homem como uma espécie de problema de sombra sustentada; desde Kant, o infinito não é mais dado, não há senão a finitude, e é neste sentido que a crítica kantiana carregava consigo a possibilidade - ou o perigo - de uma antropologia (FOUCAULT, 2001a, p. 474).

7 Esta é a acepção do termo "transcendental" que adotamos, quando tivemos de nos referir à imagem do pensamento que reconhece na representação a forma geral do conhecimento e ao tipo de filosofia - a analítica da finitude - que especifica no pensamento antropológico a repetição do positivo no fundamental, a saber: 0 transcendental como uma forma de conhecimento, não dos próprios objetos, mas admitida como a condição de toda experiência possível. No caso de Kant, 0 significado preciso do termo "transcendental" está formulado ao longo da Kritik der Reinen Vernunft (1781-87), de modo que a definição semântica desse termo depende inteiramente de um exame cuidadoso de como ele está definido ao longo da obra e quais as variações de significados que ele comporta. Todavia, é possível indicar brevemente uma definição que traduz muito bem 0 entendimento kantiano de transcendental: "[...] Chamo transcendental a todo o conhecimento que em geral se ocupa menos dos objectos, que do nosso modo de os conhecer, na medida em que este deve ser possível a priori. Um sistema de conceitos deste género deveria denominar-se filosofia transcendental" (KANT, 2001, p. 53). 
Duas tendências que podemos analisar brevemente, comparando o caso da psicologia ${ }^{8}$ analisada por Foucault a certa tendência ou perspectiva atual na filosofia são, por um lado, a descoberta, com a antropologia como analítica do homem, de uma espécie de solo absoluto para uma hermenêutica possível (Foucault, 2001a); o que quer dizer, em outras palavras, que desde a Filosofia moderna não cessamos mais de fazer uma exegese dos modos de ser do homem: históricos, políticos, sociais, do desejo, da linguagem, do trabalho etc. Por outro lado, uma segunda tendência converteria esse ato supremo da interpretação da realidade e do sentido numa outra coisa, em uma semiologia, como o conjunto de procedimentos pelos quais se dá a descobrir o que se deve interpretar. Mas essa situação é relativa e parcial, porque no momento seguinte ela deverá se somar à perspectiva epistemológica e ao estatuto ontológico pretendidos por uma antropologia filosófica.

Essa tal situação nos leva a crer que a possibilidade de uma analítica da finitude, de um saber ou discurso ordenado sobre o conhecimento e o ser do homem, com vista à sua totalidade ou integração, não é propriamente algo que se fundamenta em uma descoberta dita científica, positiva. Se, por um lado, o homem não é uma variável empírica qualquer, um fato puro, mas determinado pelas ocorrências da vida e pelas transformações da cultura e da história nas quais ele pensa e é objetivado, por outro, ele é precisamente a constante antropológica de um saber que pressupõe a si mesmo, a imagem do pensamento que eleva a condição da finitude humana à posição transcendental, que o admite como sujeito de todo conhecimento e, ao mesmo tempo, objeto de um saber possível. Caso essa afirmação possa ser admitida como correta, embora a ambiguidade que ela encerra seja inevitável, a possibilidade de uma analítica da finitude, então, deverá ser buscada, primeiro, na descoberta ou no reconhecimento de que o ser do homem não é uma positividade determinável empiricamente; ele só existe, isto

8 Fazemos uma vez mais referência ao texto Philosophie et psychologie, já apresentado, mas ao qual relacionamos ainda dois outros estudos nos quais, igualmente, Foucault faz passar por um exame cuidadoso o estatuto científico pretendido pelo saber psicológico e sua intrínseca relação com a Filosofia e as Ciências Humanas: La psychologie de 1850 à 1950 e La recherche scientifique et la psychologie, ambos os textos datados de 1957 e disponíveis em Dits et Écrits I (FOUCAULT, 2001a, p. 148186). 
é, só é possível pensá-lo já ao nível de uma interpretação. Esta condição fundamental, este traço idiossincrático é o que identifica e singulariza a estrutura antropológico-humanista do pensamento filosófico. Em outras palavras, o homem apenas pode ser pensado relativamente, enquanto sujeito de cultura e sujeito de linguagem, contudo, não de forma absoluta, como uma essência ou natureza empírica que antecipa as realizações humanas no tempo e formalmente. Se o homem se revela como sujeito apenas ao nível de suas manifestações culturais e históricas, então não há uma natureza ou essência a ser descoberta, mas sim uma hermenêutica possível a ser desvendada numa série infinita de interpretações que se supõem umas às outras indefinidamente.

[...] Ora, o que é interpretar, o que é tratar uma linguagem não como linguista, mas como exegeta, como hermeneuta, senão precisamente admitir que exista uma espécie de grafia absoluta que nós teremos de descobrir em sua própria materialidade, da qual devemos reconhecer em seguida que essa materialidade é significante, segunda descoberta, e da qual devemos, em seguida, descobrir o que ela quer dizer, terceira descoberta, e da qual devemos, enfim, descobrir segundo quais leis esses signos querem dizer o que eles querem dizer. [...] mas essa quarta descoberta é somente quarta em relação às três muito mais fundamentais, e estas três primeiras descobertas são a descoberta de alguma coisa que está aqui, diante de nós, a descoberta de um texto a interpretar, a descoberta de uma espécie de solo absoluto para uma hermenêutica possível (FOUCAULT, 2001a, p. 470).

Com isso, Foucault parece indicar algo fundamental, que na medida em que se faz a interpretação, não se descobre apenas uma hermenêutica possível para o pensamento; descobre-se também, e ao mesmo tempo, que o que a interpretação manifesta, o sentido, está delimitado pela materialidade do signo, pelo que o signo é capaz de dizer e segundo que regras, em função de que leis ele pode dizer o que quer dizer. Em outras palavras, é preciso que a hermenêutica seja portadora não apenas de interpretações, mas que reconheça a necessidade de uma dimensão semiológica importante. Entretanto, sabe-se que não há um código geral a partir do qual a interpretação possa formal e 
antecipadamente determinar o sentido, de modo que apenas relativamente a interpretação depende do emprego dos signos; e é nessa fissura que a dimensão epistemológica surge ainda como mais fundamental.

Contudo, porque permanece no intuito de promover tais coisas é que a estrutura antropológico-humanista do pensamento, evidenciada pela analítica da finitude, fracassa duplamente. Primeiro, porque ela comporta sempre interpretações, sobre o que é possível afirmar do ser do homem não há nada além ou aquém de interpretações. E, em segundo lugar, porque ela converte em pressupostos a resposta à interrogação de como é possível que as coisas em geral sejam dadas à representação, de como são possíveis a representação e a análise das representações. A tarefa de tornar possível a representação recai, desse modo, sobre o homem: “[...] a análise do modo de ser do homem tal qual foi desenvolvida desde o século XIX não se situa no interior de uma teoria da representação; ao contrário, sua tarefa é mostrar como é possível que as coisas em geral sejam dadas à representação, sob que condições, sobre que solo." (FOUCAULT, 1966, p. 348). Forma-se, então, um misto confuso e indesatável; ou seja, porque não é mais possível parar de interpretar, fixam-se os pressupostos, não para por um termo final ao processo orgíaco e infinito da interpretação, mas para ter um ponto de certeza de onde é possível (re)começar sempre que preciso. Um novo platonismo? Talvez, porque com frequência se afirma que para progredir em direção ao sentido é preciso retomar o ponto em que a interpretação é possível: a ideia de essencial, a ideia de fundamento, a ideia de uma natureza humana, a ideia de uma segunda natureza (a cultural); a ideia de algo a interpretar. Sobre isso, dizemos que é preciso reverter esta situação de confinamento da reflexão filosófica à estrutura antropológico-humanista do pensamento moderno, assim como Deleuze (1969) justificava a necessidade para a filosofia do futuro de reverter o platonismo 9 . Para uma filosofia, como a de Michel Foucault, segundo a qual deve-se romper

9 Sobre o tema da reversão do platonismo, referimo-nos ao texto Platon et le simulacre, publicado no Apêndice do livro de Gilles Deleuze intitulado Logique du sens (1969). Este texto é importante na medida em que nele Deleuze argumenta que com Platão funda-se o domínio que a Filosofia reconhecerá como próprio: 0 domínio da representação. “0 platonismo funda assim todo 0 domínio que a filosofia reconhecerá como seu: 0 domínio da representação preenchido pelas cópias-ícones e definido não em uma relação extrínseca a um objeto, mas numa relação intrínseca ao modelo ou fundamento" (1969, p. 298-299). 
com os pressupostos e a ortodoxia do pensamento, a antropologia é indefensável. Sobre isso, Foucault afirmou:

[...] eu direi simplesmente que houve uma espécie de sono antropológico no qual a filosofia e as ciências do homem ficaram, de alguma maneira, fascinadas e adormecidas umas pelas outras, e que é preciso acordar deste sono antropológico, como outrora acordava-se do sono dogmático (2001a, p. 476).

A julgar pelo que essa argumentação nos permite pensar a respeito das questões controversas e das muitas opiniões disputadas pelos autores contemporâneos nessa matéria, conclui-se pela importância de aprofundar a análise do modo como essa configuração antropológica do pensamento, a analítica da finitude, se delineia no campo dos estudos filosóficos contemporâneos, como concepção fundamental e específica que identifica a Filosofia com um tipo universalista de antropologia.

No mais, a possibilidade de escapar à ambiguidade evidenciada pela analítica da finitude, a ideia de que "[...] os limites do conhecimento fundam positivamente a possibilidade do saber" (FOUCAULT, 1966, p. 327), dominante na Filosofia moderna é, do mesmo modo, a necessidade de romper com a ortodoxia do pensamento filosófico na atualidade. Ademais, a crítica é tão-somente possível se conjugada a uma prática de invenção. Para dizer com Deleuze (1997), à crítica filosófica deve corresponder uma clínica do pensamento, ou seja, uma renovação das formas de pensar e dos meios de expressão filosófica. Talvez, a começar, por uma renovação que venha do estilo.

\section{Considerações finais}

A partir do emprego do método arqueológico, e este foi o caso do livro Les mots et les choses, Foucault (1966) procurou analisar certa ordem na disposição das coisas para descobrir como foi possível o saber em determinadas épocas. Mas essa análise arqueológica rapidamente se revelaria, na verdade, como uma crítica às filosofias de tipo 
antropologizante, e a justificação para a adoção de uma antropologia filosófica estaria ameaçada em face da crítica contemporânea.

Não nos parece certo admitir que na atualidade esse discurso especificamente antropológico tenha desaparecido de todo das Ciências Humanas, de seus métodos ou do estudo do conhecimento e do ser do homem; e este também parece ser o caso da Filosofia. Isso quer dizer que mesmo uma filosofia contemporânea não estaria, em relação às Ciências Humanas, menos imune aos efeitos desse modelo ou imagem do pensamento que encontra na estrutura antropológico-humanista do pensamento sua fundamentação e a justificação para que ela, inclusive, participe do destino de uma analítica da finitude: o estudo do ser do homem como sujeito e, ao mesmo tempo, objeto de um saber possível (FOUCAULT, 2001a, p. 636).

Este é, com efeito, o traço distintivo fundamental ao paradigma antropológico, isto é, a repetição do positivo no fundamental como condição da finitude humana, como exigência para que o sujeito seja pensado a partir da finitude que o constitui. Por um lado, esta finitude se manifesta nas positividades dos saberes empíricos sobre o homem que o determinam pela vida, pelo trabalho e pela linguagem; mas, por outro, e essa é a posição ambígua a que está subsumida a concepção moderna de sujeito, essas formas exteriores que marcam a existência do homem no mundo só podem ser apreendidas a partir e fundamentalmente da própria finitude. Remonta-se, assim, da finitude das empiricidades a uma finitude mais fundamental, a partir da qual a primeira é dada ao conhecimento do sujeito:

[...] Todos estes conteúdos que seu saber lhe revela como sendo exteriores a si mesmos e mais antigos que seu nascimento, se antecipam sobre ele, sobrecarregam-no com toda solidez e o atravessam como se ele fosse apenas um objeto da natureza ou um rosto que deve desaparecer na história. A finitude do homem se anuncia - e de uma forma imperiosa - na positividade do saber" (FOUCAULT, 1966, p. 324).

Sabemos, todavia, que essa situação que caracteriza em grande parte a Filosofia moderna, nela compreendidos inclusive o seu método e objetivos, não é condição histórica apenas particular a essa matéria. 
Mas corresponde, como explica Foucault (1966), à configuração do pensamento filosófico que se estende da Modernidade até o presente a registros próprios de uma concepção dogmática da Filosofia, de tal modo que a possibilidade de escapar à ortodoxia de pensamento de que essa imagem antropológica é portadora consiste, precisamente, na necessidade de romper com a representação enquanto paradigma do pensamento filosófico na atualidade. A respeito desta situação problemática do pensamento filosófico na atualidade, Foucault ponderou que:

A Antropologia constitui talvez a disposição fundamental que comandou e conduz o pensamento filosófico desde Kant até nós. Disposição essencial, pois que faz parte de nossa história; mas em via de se dissociar sob nossos olhos, pois começamos a nela reconhecer, a nela denunciar de um modo crítico, a um tempo, o esquecimento da abertura que a tornou possível e o obstáculo tenaz que se opõe obstinadamente a um pensamento por vir (1966, p. 353-354).

Sabemos, igualmente, que a Filosofia moderna ao indicar o aparecimento de um domínio de questionamentos sobre o homem na cultura ocidental fez surgir, como concepção fundamental à formação histórica desse novo regime de saber, o conceito de finitude humana, e foi a partir desta épistémè, a analítica da finitude, que se tornou possível a propositura de uma configuração filosófica - isto é, antropológica - específica às Ciências Humanas na atualidade. Desse modo, não é mais com base em uma concepção essencialista do sujeito, de uma natureza humana concebida abstratamente, e nem, por outro lado, com base em uma concepção racionalista e naturalista que doravante se inscreve na história a pesquisa pelo conhecimento e o ser do homem. Ao contrário, é a partir da condição positiva dos saberes científicos que tomam o homem naquilo que ele tem de empírico, desse a priori histórico que não é senão a finitude do homem, que vemos delinear-se para o pensamento contemporâneo o estudo filosófico da existência humana e de sua realização histórica. É a transformação da finitude humana em limite positivo do conhecimento: “[...] o limite não se manifesta como determinação imposta do exterior ao homem (porque ele tem uma natureza ou história), mas como finitude fundamental que repousa apenas sobre 
o seu próprio fato e se abre sobre a positividade de todo limite concreto." (FOUCAULT, 1966, p. 326). Mas, como Foucault preferiu dizer a respeito do esforço contemporâneo de "desenraizamento" da antropologia, a crítica possível à imagem dogmática do pensamento é o limiar contemporâneo a partir do qual a Filosofia pode recomeçar a pensar; isto é, não é mais nem menos "[...] do que o desdobrar de um espaço onde, enfim, é de novo possível pensar." (1966, p. 353).

\section{Referências}

DELEUZE, G. Crítica e clínica. São Paulo: Ed. 34, 1997.

DELEUZE, G. Différence et répétition. Paris: Presses Universitaires de France, 1976.

DELEUZE, G. Foucault. São Paulo: Brasiliense, 1988.

DELEUZE, G. Logique du sens. Paris: Éditions de Minuit, 1969.

DELEUZE, G. Nietzsche et la philosophie. (6ª ed.). Paris: Presses Universitaires de France, 1983.

DELEUZE, G. Proust e os signos. Rio de Janeiro: Forense Universitária, 1987.

DREYFUS, H. L.; RABINOW, Paul. Michel Foucault: beyond structuralism and hermeneutics. (2ae ed.). Chicago: The University of Chicago Press, 1983.

FOUCAULT, M. La psychologie de 1850 à 1950. In: DEFERT, Daniel; EWALD, François; LAGRANGE, Jacques (Eds.). Dits et écrits I: 1954-1975. Paris: Éditions Gallimard, 2001a, p. 148-165.

FOUCAULT, M. La recherche scientifique et la psychologie. In: DEFERT, Daniel; EWALD, François; LAGRANGE, Jacques (Eds.). Dits et écrits I: $1954-$ 1975. Paris: Éditions Gallimard, 2001a, p. 165-186. 
FOUCAULT, M. Le souci de la vérité. In: DEFERT, Daniel; EWALD, François; LAGRANGE, Jacques (Eds.). Dits et écrits II: 1976-1988. Paris: Éditions Gallimard, 2001b. p. 1487-1497.

FOUCAULT, M. Le sujet et le pouvoir. In: DEFERT, Daniel; EWALD, François; LAGRANGE, Jacques (Eds.). Dits et écrits II: 1976-1988. Paris: Éditions Gallimard, 2001b, p. 1041-1062.

FOUCAULT, M. Les mots et les choses: une archéologie des sciences humaines. Paris: Éditions Gallimard, 1966.

FOUCAULT, M. Philosophie et psychologie. In: DEFERT, Daniel; EWALD, François; LAGRANGE, Jacques (Eds.). Dits et écrits I: 1954-1975. Paris: Éditions Gallimard, 2001a, p. 466-476.

FOUCAULT, M. Polémique, politique et problématisations. In: DEFERT, Daniel; EWALD, François; LAGRANGE, Jacques (Eds.). Dits et écrits II: 19761988. Paris: Éditions Gallimard, 2001b. p. 1410-1417.

FOUCAULT, M. Qu'est-ce que les Lumières? In: DEFERT, Daniel; EWALD, François; LAGRANGE, Jacques (Eds.). Dits et écrits II: 1976-1988. Paris: Éditions Gallimard, 2001b. p. 1498-1507.

FOUCAULT, M. Qui êtes-vous, professeur Foucault? In: DEFERT, Daniel; EWALD, François; LAGRANGE, Jacques (Eds.). Dits et écrits I: 1954-1975. Paris: Éditions Gallimard, 2001a, p. 629-648.

FOUCAULT, M. Une esthétique de l'existence. In: DEFERT, Daniel; EWALD, François; LAGRANGE, Jacques (Eds.). Dits et écrits II: 1976-1988. Paris: Éditions Gallimard, 2001b. p. 1549-1554.

FOUCAULT, M. What is Enlightenment? In: DEFERT, Daniel; EWALD, François; LAGRANGE, Jacques (Eds.). Dits et écrits II: 1976-1988. Paris: Éditions Gallimard, 2001b, p. 1381-1397. 
HUME, D. Tratado da natureza humana: uma tentativa de introduzir o método experimental de raciocínio nos assuntos morais. São Paulo: Ed. UNESP/ Imprensa Oficial do Estado, 2001.

KANT, I. Crítica da razão pura. (5ª ed.). Lisboa: Fundação Calouste Gulbenkian, 2001.

Recebido: 20/09/2016

Received: 09/20/2016

Aprovado: 30/10/2016

Approved: 10/30/2016 